\title{
A review on failure characteristics of polymer gear
}

\author{
Wafiuddin Md Ghazali ${ }^{1}$, Daing Mohamad Nafiz Daing Idris ${ }^{1, *}$, Azizul Helmi Sofian ${ }^{2}$, \\ Januar Parlaungan Siregar ${ }^{1}$ and Ismail Ali Abdul Aziz ${ }^{1}$ \\ ${ }^{1}$ Faculty of Mechanical Engineering, Universiti Malaysia Pahang, 26600 Pekan, Pahang, Malaysia \\ ${ }^{2}$ Faculty of Chemical \& Natural Resources Engineering, Universiti Malaysia Pahang, 26300 \\ Gambang, Kuantan, Pahang, Malaysia
}

\begin{abstract}
Polymer are now widely used as substitute material for steel gear in low load devices. Its failure differs from gears made of steel, thus it is important to categorize the failures shown by polymer gears. Several previous studies noted that wear detection, microstructure surface condition monitoring, weight loss and temperature detection can be used in detecting failure of polymer gear. This article reviews the failure detection method mentioned above. Other researcher works were studied and their findings were extracted in order to identify the methods they used. The most common method used was wear detection and it was supplemented by other methods such as microstructure surface condition monitoring. Failures shown by polymer can be concluded to be tooth breakage, tooth deformation, material removal and surface fatigue.
\end{abstract}

\section{Introduction}

Polymer are chosen to replace steel gear in low load devices due to the technical advantage and economic gains. The advantages of polymer gear is ability to operate with small amount of lubrication, light in weight material and low operating noise [1] compared to metal gear. However, considerations such as; working environment, strength, weight, material properties and cost [2] must be carefully considered when deciding to replace steel with polymer. Standards for polymer gear like AGMA [3] and British Standard [4] can be referred when designing the gears.

Polymer gear failures are different from steel because of the material properties of polymer are totally different. An example of polymer gear failure is melting of material which does not occur for steel gears. These type of failure can be categorized under thermal damage. This article reviews four types of failure characteristic; wear, microstructure surface condition monitoring, weight loss and thermal damage which is shown in Fig. 1. These characteristic are often studied together as they complement one another. The other two characteristics is not discussed in this article.

Wear detection is the most commonly used method [5] to determine failure as it covers a variety of conditions such as cracks, breakage and debris formation [6]. Microstructure

\footnotetext{
* Corresponding author: daingnafiz@ump.edu.my
} 
surface condition monitoring provides a ready and quick method to inspect the surface failure [7] which are not visible during wear detection. Weight loss failure characteristic are only suitable for gears made from pure polymer as reinforcements may affect the weight of gear. In thermal damage characteristic, temperature detection has a vital role to determine at what temperature damage starts to occur.

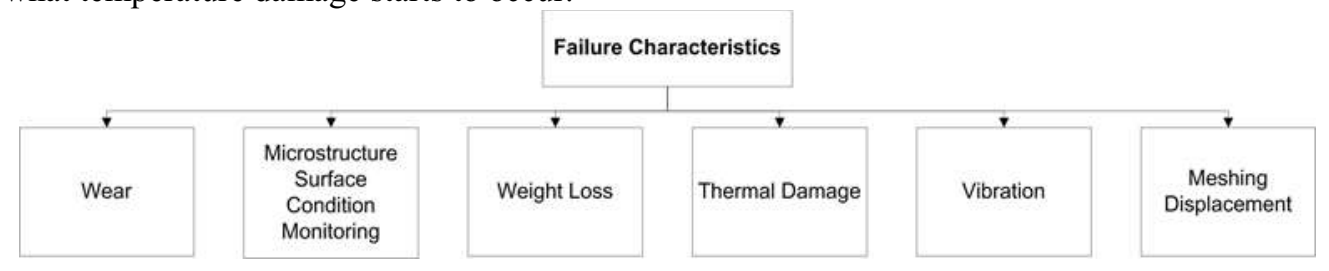

Fig. 1. Types of failure characteristics for polymer gear.

\section{Failure characteristics}

\subsection{Wear}

There are many types of failure that can be categorized under wear, such as crack or breaking, tooth thickness reduction and debris formation. Each review will include all known wear formation of polymer gear.

\subsubsection{Wear debris formation}

Acetal gear were found to have different failure compared to Nylon gear as reported by K. Mao et al [8]. Polymer gear wear can be divided into three stages; running in, linear and final rapid wear as shown in Table 1 . The wear debris size increases as the gear approaches final wear period. When Acetal gears were tested in the high range load, $10-16.1$ N.m, the wear debris formed immediately after the test started. When Nylon gears were tested at high load, 10 N.m, it fractures after going through running in and linear wear period. The gear made from Acetal failed by melting and in Nylon by fracture as shown in Fig. 2.

The same result was also obtained by W. Li et al [9] in their research where the test gears were paired with different materials. Acetal gear started to melt at load torques higher than 9 N.m and fracture occurs when load is 10 N.m and above. However, the wear performance improved when it is paired with dissimilar material where Acetal as the driver gear and Nylon as the driven gear, this pair showed the highest performance from other pairs which can be seen in Fig. 3.

Table 1. Stages of polymer gear wear.

\begin{tabular}{|c|l|}
\hline Phase & \multicolumn{1}{c|}{ Explanation } \\
\hline Running in wear & Occurs for a short time but the amount of wear is high \\
\hline Linear wear & Low amount of wear can be seen but is progressive \\
\hline Final rapid wear & $\begin{array}{l}\text { High wear rate but small amount of debris, indicating debris is due to } \\
\text { deformation undergone by the polymer gear caused by thermal effects }\end{array}$ \\
\hline
\end{tabular}




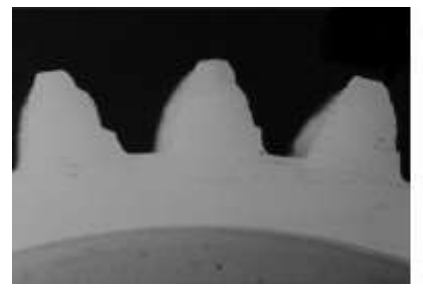

Nylon

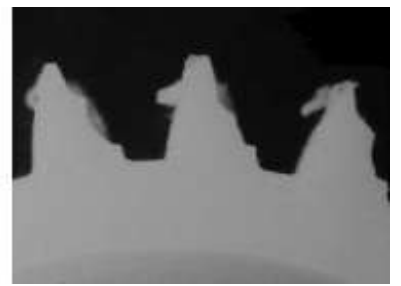

Acetal

Fig. 2. Wear on polymer gears with module $2 \mathrm{~mm}$ and 30 gear tooth [8].

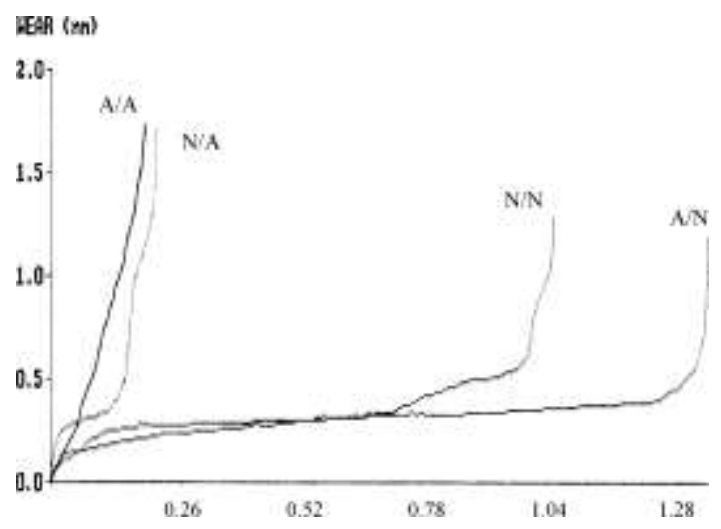

Fig. 3. Results on Nylon/Acetal (N/A), Acetal/Nylon (A/N), Acetal/Acetal (A/A) and Nylon/Nyon $(\mathrm{N} / \mathrm{N})$ gear pairs [9].

\subsubsection{Tooth thickness reduction}

Wear rates for Acetal gear produced by machine cut and injection moulding are independent to the manufacturing process as reported by $\mathrm{K}$. Mao et al [10]. The gears undergo testing at load $6-9 \mathrm{Nm}$ at $100 \mathrm{rpm}$ and undergo wear in three phases. The running-in and linear phase produced little wear debris, but in the rapid wear period, wear debris increased and so does the wear rate. After about $33 \%$ of tooth thickness removed, the gear started to fail. An incremental step loading (load is incrementally added without changing the test gears) was used and it was compared to the conventional procedure (test gears is changed for every load value). The result obtained showed that the incremental step loading test produces adequate result and can be completed within hours compared to conventional testing which takes up weeks. It was also noted that bending occurred when the material is momentarily melted causing it to jump out of mesh. The repeated motion of sliding at addendum and dedendum region produced heat caused by the friction of the tooth surface leading to adhesive wear.

The various types of failure in unreinforced and reinforced Nylon 66 gear was studied by S. Senthilvelan and R. Gnanamoorthy [11] using tooth thickness and weight loss measurement technique. Unreinforced and reinforced Nylon 66 gears were meshed with a stainless steel (SS316) gear. Fig. 4 shows the deformation of teeth region undergone by the glass reinforced Nylon 66 gear. Reinforced gears showed a uniform material loss compared to unreinforced gears because glass fiber have better adhesion to the matrix compared to carbon fibre. Wear of tooth flank region in glass reinforced fibre is caused by softening of material and scraping by opposing stainless steel gear tooth. The wear occurred is due to the low thermal resistance of the material. In the case of carbon fibre reinforced gear, no appreciable tooth deformation was present due to high stiffness and good thermal resistance 
of the material. This result was obtained at the test parameter of $1000 \mathrm{rpm}$ rotational speed and loads ranging from 1.5 N.m to 3 N.m.

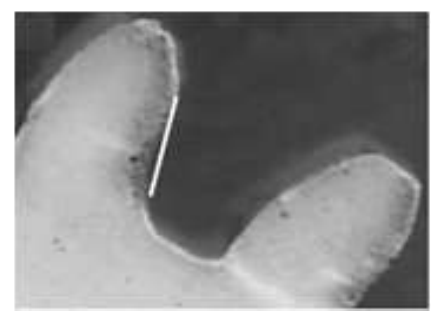

Fig. 4. Tooth thickness reduction due to scraping of steel gear tooth [11].

\subsubsection{Cracks}

Cracks often occur at the root of the tooth and will propagate causing tooth breakage. The effect of rotational speed on the performance of unreinforced and glass reinforced Nylon 6 was studied by S. Senthilevan and R. Gnanamoorthy [12]. The glass fibre reinforced gear showed improvement in mechanical strength and thermal deformation. They noted that the performance of gears was influenced by the load applied. The performance was only influenced by speed at the higher load condition. Gear root tooth crack and tooth wear were observed occurring at lower load, $8 \mathrm{MPa}$ for both materials. When the load is higher, plastic deformation occurs on the unreinforced gear and at $15 \mathrm{MPa}$ deformation starts to occur in glass fibre reinforced gear. At low stress levels, gear tooth root cracking and tooth wear was the main factor of failure, and in the higher stress level, deformation of material at high temperature causes failure. Modification on gear tooth made from Nylon 6 was reported by H. Imrek [13] and the failure for each design was studied. The tooth was modified as seen in Fig. 5 so that the single mesh area was increased thus reducing the load and temperature of the area. This reduces the wear rate and improves the overall teeth temperature. The unmodified gear showed cracking at the pitch area in Fig. 5 while in modified gear, cracking occurred at tooth roots.

Modification of gear tooth was also studied by H. Duzcukoglu [14] where holes are introduced to the tooth body of the gear. This serves as a cooling mechanism and to improve the heat distribution. Gears with modification shown smooth wear transition compared to unmodified gears. As the tooth load increases, the tooth profile wear becomes more noticeable at the tooth root and tooth tip region. It was concluded that wear occurs due to softening and detachment of material from the contact area and with the modification, the damage is delayed with the help of increased heat transfer from the gear. The effect of different hub type on the spur gear performance was studied by S.

Senthilvelan and R. Gnanamoorthy [15] using gears made from Nylon 66 and reinforced with carbon fibre. The hub was made from Nylon 66 and in cylindrical or spline shape. At $15 \mathrm{MPa}$ of bending stress, both unreinforced and reinforced gears showed wear at tooth surface and flank. When the bending stress is at $20 \mathrm{MPa}$, the gear fitted with cylindrical hub failed at the gear and hub joint at $2 \times 10^{5}$ cycle and the gear with spline hub showed wear characteristics such as cracks at tooth root region. The failure between circular hub and gear is caused by the joint failure meanwhile in spline hub and gear the failure is caused by the gear tooth. The failure for unreinforced and reinforced gear were the same in the spline hub. 
a

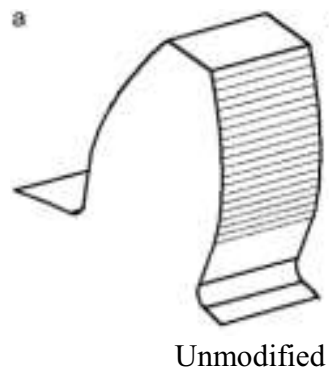

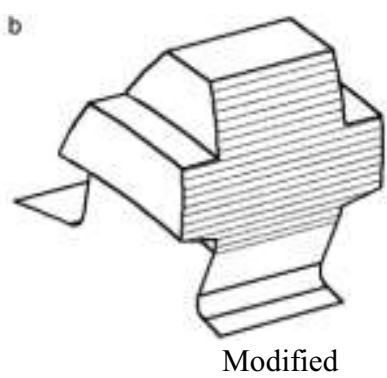

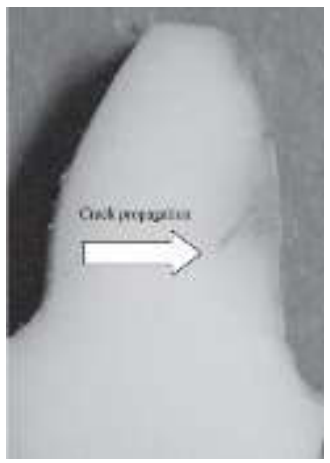

Fig. 5. Gear profile models, arrow indicates crack propagation [13].

\subsection{Microstructure surface condition monitoring}

This method is used to detect micro crack or deformation on the gear surface which are not visible with naked eye. With the introduction of composite polymer, this method becomes more important as it is capable to inspect the fibre structure and alignment.

Scanning electron micrograph (SEM) was used by A. R. Breeds et al [16] in order to study the surface condition. Three major interest region were dedendum, addendum, and pitch line. With the help of SEM, they were able to detect large pits or scoops of material were removed at the dedendum, smooth surface due to wear at addendum caused by sliding and rolling motion of gears and the formation of a ridge at pitch line caused by rolling. An SEM examination around the gear tooth pitch and root areas were conducted by K. Mao et al [10] to determine whether wear occurs at that region. From the gear mesh theory, there is nearly zero friction around the pitch point, however the images from SEM showed otherwise. This shows that SEM can also be a reliable method to detect failure in polymer gears. Fig. 6 shows the difference of wear occurring at the tip and pitch point of the gear.

The effect of fibre orientation was analyzed using SEM by S. Sentilvelan and R. Gnanamoorthy [11]. A perpendicular aligned fibre orientation showed better performance where it helps slowing the crack growth, thus improving the gear life. In the glass reinforced gear, matrix nylon material was found adhered to the protruded glass fibre on the fracture surface. The cracked surface showed few cavities and nearly flat. This is due to the better adhesion of glass fibre and nylon matrix. Molten smeared layers were also seen on the surface. A high number of cavities were observed in the carbon reinforced gear cracked surface due to the poor adhesion between carbon fibres and nylon matrix. Molten material was absent due to better thermal properties of the carbon fibre reinforced Nylon 66 . The fibre orientation is influenced by the gate location and tooth geometry. Both glass and carbon reinforced show poor wear resistance compared to unreinforced gear at the investigated condition. Molten material can be seen on the unreinforced Nylon 66 in Fig. 7 and on glass fibre reinforced Nylon 66 in Fig. 8. There was no molten material present on carbon fibre reinforced Nylon 66. However, cavities are present on both glass fibre and carbon fibre reinforced Nylon 66 in Fig. 8.

The surface of loading tooth was inspected by H. Duzcukoglu et al [17] to determine the presence of transverse crack. It was found that the transverse cracked occurred due to thermal softening caused by accumulated heat. These cracks shall merge and grow resulting removal of material in the shape of flakes. The possibility of controlling wear by applying coatings on tooth flanks were studied by K. Dearn et al [18]. Five types of coating were used; PTFE, boron nitride, molybdenum disulphide and graphite to protect the gear. SEM 
was used to study the surface of each gear with different coatings. PTFE and graphite provide most optimum protection as it lowers the friction between gear tooth, reduces running temperature and subsequently the wear of gears. However, it is possible that the coating will lose its effectiveness as the protection film wears over time.

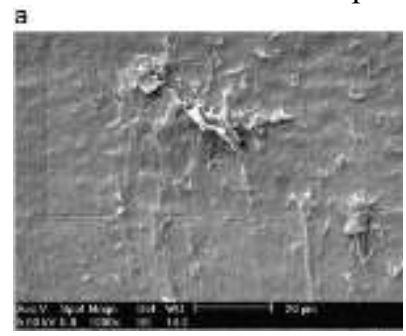

Wear at tip

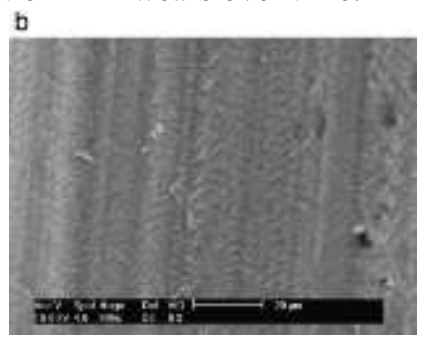

Wear at pitch

Fig. 6. SEM image of wear on polymer gear occurring at tip and pitch [10].

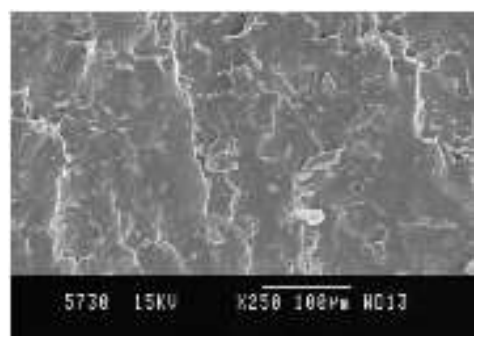

Fig. 7. Surface condition of unreinforced Nylon 66 [11].

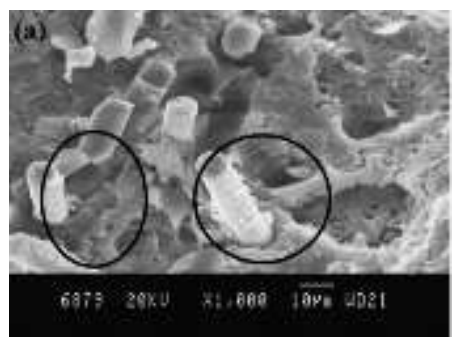

Glass Fibre Reinforced Nylon 66

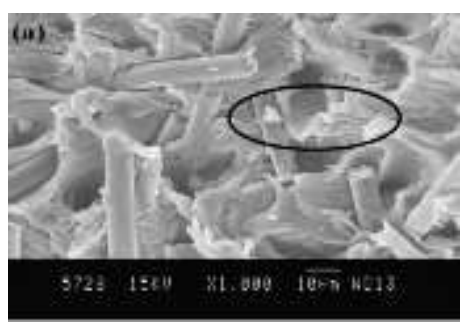

Carbon Fibre Reinforced Nylon 66

Fig. 8. Surface condition of polymer gear [11].

\subsection{Weight loss}

This characteristic was found to be acceptable if gears were made using pure polymer. However, if it is made from composite, it become less reliable as the weight is affected by the composition of fibre and moisture or water presence. This was shown by N. A. Wright and S. N. Kurenka where they introduced a pair of control gear in their research [19]. They stated that the weight loss from running test can be considered as one of the method to determine failure, if only the material used does not have a high affinity for water. They noted that Polyamide 66 absorbs a significant amount of water, therefore the introduction of control gears and it was placed on the drive gearbox. They calculated the weight loss by subtracting the weight loss by control gear from the total measured weight loss by the test gear.

The weight loss method was used by C. H. Kim [20] to determine the wear volume of both Nylon and Acetal pinion. The pinion had three design, a solid gear tooth body, a 
drilled hole on the gear tooth body and a hole inserted with steel pin. The hole type and insert type showed less wear rate than the solid one. In the Nylon gear, hysteric heat loss was decreased by the hole in the tooth, while in the steel pin type, heat is absorbed and distributed by the pin. Both design led to decrease in wear rate and degradation of Nylon material. In the case of Acetal pinion, the variation of cross section increased the specific wear rate. The decrease of cross section area led to deformation and plastic flow on the Acetal pinion. This will lead to severe wear due to interference and severe contact between the Acetal pinion and steel driver gear. The wear rate in Nylon pinion decreased by over $30 \%$ and an increase in service life by $415 \%$. While the Acetal pinion, it causes increase in wear, therefore this method can only be applied to visco-elastic material only.

The wear resistance of carbon nanotube reinforced Acetal gear was studied by S. Youseff [21] by determining the weight loss of the gear. It was then compared to results from previous research [22]. The results showed that the average wear resistance of Acetal reinforced with carbon nanotube compared to Acetal improved significantly. Spur gear improved by $28 \%$, helical gear by $35 \%$, bevel gear by $44 \%$ and lastly worm gear up to $47 \%$.

\subsection{Thermal damage and temperature detection using thermal camera or temperature sensor}

In this method, temperature of the gears is taken during or after they were tested. Some researcher also used data acquisition system to record the operating temperature. This failure detection method is essential as different loads will influence the running temperature and affect the material properties when it reaches the glass transition temperature or the melting temperature.

The failure mode of polymer and polymer composite was found to be different as shown by S. Sentilvelan and R. Gnanamoorthy [11]. The gears were made from Nylon and reinforced with carbon or glass fibre. They also found that the surface temperature of unreinforced gear was higher compared to reinforced gear. In the reinforced Nylon, carbon reinforced had a lower temperature than glass reinforced. The reinforced gears lower temperature was contributed by a better tooth stiffness, lower friction and good thermal properties. A high tooth stiffness prevents tooth deflection which contribute to less unwanted contact between tooth surface which causes heat. The improved heat dissipation ability increased the gears life considerably. The introduction of cooling holes was reported by H. Duzcukoglu [17] in order to decrease thermal damage. Three design of gears were studied, first is unmodified, the second gear had a hole drilled at the pitch point of the gear tooth and the third design have holes at the pitch point and on the body of the tooth as seen in Fig. 9. The temperature was detected using a non-contact infrared temperature sensor and recorded on a PC by using data acquisition system. The first design failed at the vicinity of the pitch diameter, caused by softening. This was due to the gear inability to emit heat which was accumulated during the running process. As the load increases, the thermal damage also increased. This causes the material to soften and severe tooth deformation occurs. In the second design, partial thermal softening at the pitch region and tooth root region was observed. The amount of thermal damage was reduced by using this design, however, there is still damage on the surface of the loading tooth. For the third design, only thermal damage initiation was observed at the high load, 18.1 N.m. The heat produced in each design is from the friction between the driver and driven gear. The result from heat produced affecting the gear tooth can be seen in Fig. 9. 


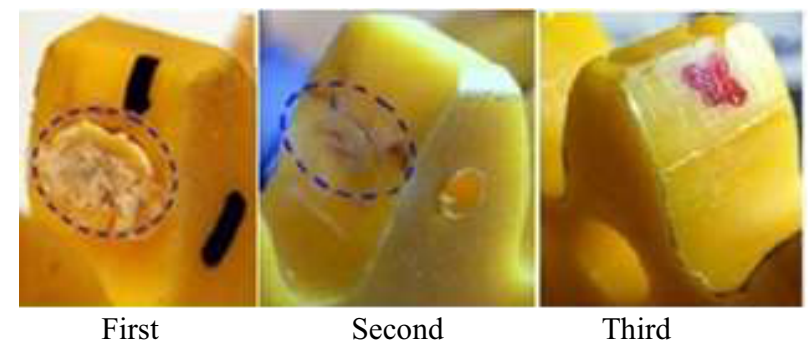

Fig. 9. Tooth condition for each design when the load is at $6.1 \mathrm{~N} / \mathrm{mm}$ [17].

A design in which an internal hole or steel pin inserts are introduced to the tooth body was presented by C. H. Kim [20] to improve heat transfer process and stress concentration. Temperature of the tooth surface was measured and investigated using a non-contact type temperature sensor. Three load value was used, which are $9.8 \mathrm{~N} / \mathrm{mm}, 19.6 \mathrm{~N} / \mathrm{mm}$ and 29.4 $\mathrm{N} / \mathrm{mm}$. At first load value, the hole type pinion had the lowest temperature value but have a higher fluctuation. The steel insert pinion has a slightly higher temperature, but the temperature maintained. When the load is $19.6 \mathrm{~N} / \mathrm{mm}$, the insert type pinion showed better performance than the others. At the highest test load, fracture can be seen from all types of design. the insert type took the longest time before failing followed by hole type and lastly solid type. It can be noted that the decrease in tooth temperature will result in better life and reduction of wear.

Polymer gear can fail in two typical ways, fatigue or sudden melting as reported in the research by A. Pogacnik and J. Tavcar [23]. A new multilevel accelerated testing procedure was proposed by the authors and the results which are life span and gear temperature were compared with a calculation procedure. The temperature was recorded using a thermal camera and the materials were PA 6, PA 6 with 30\% glass fibres and Polyacetal. The maximum gear temperatures and load levels are different for every pair of materials. PA6/PA6 pair generated the highest temperature due to the high coefficient of friction. POM/PA6 pair gives the lower temperature due to lower coefficient of friction. The melting of gears was a consequence of overload and an increase in temperature. By avoiding problematic material combination, the failure due to thermal characteristic can be avoided.

The effect of different surface roughness was studied by J. Mertens and S. Sentilvelan [24] where three different value of coefficient of friction studied. Three stainless steel gear with coefficient of friction $3.8-4.1 \mu \mathrm{m}, 2.5-2.8 \mu \mathrm{m}$ and $1.9-2.2 \mu \mathrm{m}$ was mated with polypropylene gear. The surface temperature of test gear was measured using a non-contact infra-red sensor. The frictional values of the surface are influenced by the hardness and micro geometry of the stainless steel gear. When a polymer slides on steel, adhesion and deformation occurs, contributing to the friction between those two surface. At a higher load, the surface interaction will increase, causing the friction, wear and temperature to increase which can be seen in Fig. 10. Polymer gear will generate more heat when meshed with surfaces having a high friction coefficient thus affecting the performance of the polymer gear. It can be seen that Gear A have the highest friction followed by B and C which relates to the higher temperature produced by $\mathrm{A}$ and followed by $\mathrm{B}$ and $\mathrm{C}$ at each load. 


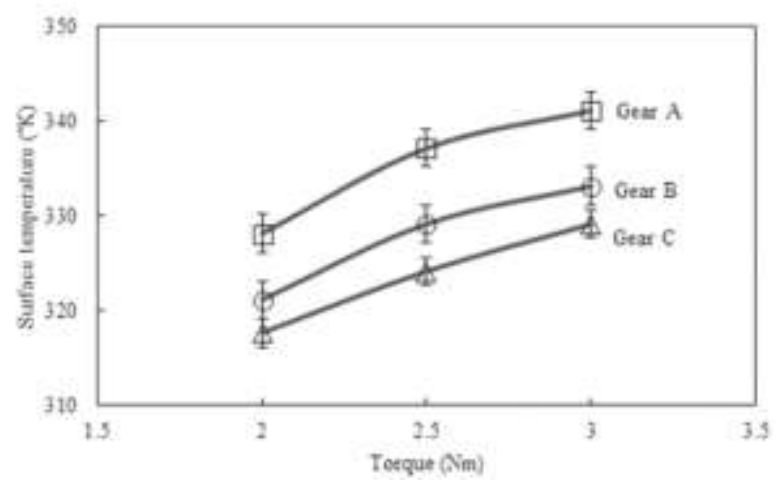

Fig. 10. Comparison of surface temperature for test gears [25].

\section{Conclusions}

From the reviewed articles, it can be concluded that detection of wear, microstructure surface condition monitoring, weight loss and thermal damage and temperature detection are the most prominent method alongside vibration and meshing displacement in order to detect failure in polymer gears. Most of the failures occurred due to the limitation of material, such as the load handling capability and thermal properties. In order to optimize the usage of polymer gear in applications, the operating parameters such as load and running temperature must be calculated beforehand so that the working environment of the polymer gear is the most optimum.

The authors would like to express their gratitude to Universiti Malaysia Pahang and Automotive Excellence Centre (AEC), UMP for their financial support under grant number RDU150386.

\section{References}

1. R. L. Mort, Machine Elements in Mechanical Design: Pearson Education South Asia Pte Ltd, (2006).

2. J. L. Elmquist. Deciding When to Go Plastic. Gear Technology. 46 - 47 (2014).

3. A. G. M. Association, "Standard 1106-A97. Tooth Proportions for Plastic Gears," ed. Washington DC: American Gear Manufacturers Association.

4. B. S. Institution, "BS 6168. Specification for non-metallic spur gears," ed. London, (1987).

5. K. M. Marshek and P. K. C. Chan, "Qualitative analysis of plastic worm and worm gear failures," Wear, vol. 66, pp. 261-271, 1981/02/16 (1981).

6. H. J. Watson, "5-Wear of gears," Tribology, 2, pp. 212-216, 1969/11/01 (1969).

7. B. A. Shaw, J. T. Evans, T. F. Page, "Scanning electron acoustic microscopy imaging of sub-surface microcracks produced in gear fatigue," Journal of Materials Science Letters, 13, pp. 1551-1554, (1994).

8. K. Mao, W. Li, C. J. Hooke, and D. Walton, "Friction and wear behaviour of acetal and nylon gears," Wear, 267, pp. 639-645, 6/15/ (2009).

9. W. Li, A. Wood, R. Weidig, and K. Mao, "An investigation on the wear behaviour of dissimilar polymer gear engagements," Wear, 271, pp. 2176-2183, Jul 29 (2011). 
10. K. Mao, P. Langlois, Z. Hu, K. Alharbi, X. Xu, M. Milson, et al., "The wear and thermal mechanical contact behaviour of machine cut polymer gears," Wear, 332-333, pp. 822-826, 5// (2015).

11. S. Senthilvelan and R. Gnanamoorthy, "Damage Mechanisms in Injection Molded Unreinforced, Glass and Carbon Reinforced Nylon 66 Spur Gears," Applied Composite Materials, 11, pp. 377-397, (2004).

12. S. Senthilvelan and R. Gnanamoorthy, "Effect of rotational speed on the performance of unreinforced and glass fiber reinforced Nylon 6 spur gears," Materials \& Design, 28, pp. 765-772, // (2007).

13. H. İmrek, "Performance improvement method for Nylon 6 spur gears," Tribology International, 42, pp. 503-510, 3// (2009).

14. H. Düzcükoğlu, "Study on development of polyamide gears for improvement of loadcarrying capacity," Tribology International, 42, pp. 1146-1153, 8// (2009).

15. S. Senthilvelan and R. Gnanamoorthy, "Selective Carbon Fiber Reinforced Nylon 66 Spur Gears: Development and Performance," Applied Composite Materials, 13, pp. 4356,( 2006).

16. A. R. Breeds, S. N. Kukureka, K. Mao, D. Walton, and C. J. Hooke, "Wear behaviour of acetal gear pairs," Wear, 166, pp. 85-91, 1993/06/15 (1993).

17. H. Düzcükoğlu, R. Yakut, and E. Uysal, "The Use of Cooling Holes to Decrease the Amount of Thermal Damage on a Plastic Gear Tooth," Journal of Failure Analysis and Prevention, 10, pp. 545-555, (2010).

18. K. D. Dearn, T. J. Hoskins, D. G. Petrov, S. C. Reynolds, and R. Banks, "Applications of dry film lubricants for polymer gears," Wear,. 298-299, pp. 99-108, 2/15/ 2013.

19. N. A. Wright and S. N. Kukureka, "Wear testing and measurement techniques for polymer composite gears," Wear, 251, pp. 1567-1578, 10//(2001).

20. C. H. Kim, "Durability improvement method for plastic spur gears," Tribology International, 39, pp. 1454-1461, 11// (2006).

21. S. Yousef, T. A. Osman, A. Abdalla, and G. Zohdy, "Wear Characterization of Carbon Nanotubes Reinforced Acetal Spur, Helical, Bevel and Worm Gears Using a TS Universal Test Rig," JOM, pp. 1-8, 2014/12/23( 2014).

22. S. Yousef, A. Khattab, M. Zaki, and T. A. Osman, "Wear Characterization of Carbon Nanotubes Reinforced Polymer Gears," Nanotechnology, IEEE Transactions on, 12, pp. 616-620, (2013).

23. A. Pogačnik and J. Tavčar, "An accelerated multilevel test and design procedure for polymer gears," Materials \& Design, 65, pp. 961-973, 1// 2015.

24. A. J. Mertens and S. Senthilvelan, "Effect of Mating Metal Gear Surface Texture on the Polymer Gear Surface Temperature," Materials Today: Proceedings, . 2, pp. 17631769, // (2015).

25. A. J. Mertens and S. Senthilvelan, "Effect of mating metal gear surface texture on the polymer gear surface temperature," Materials Today-Proceedings. 2, pp. 1763-1769, (2015). 